Produto \& Produção, vol. 12, n. 2, p. 24 - 47, jun. 2011

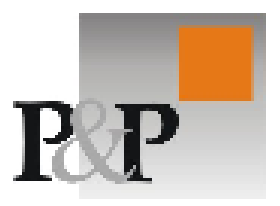

\title{
Prestadores de serviços logísticos (PSL) - Identificando suas Competências
}

Recebido em 21/02/2011. Aceito em 19/05/2011.

\section{Mauro Vivaldini \\ Professor UNIMEP \\ mavivald@unimep.br}

Esse trabalho discute as competências necessárias ao Prestador de Serviços Logísticos (PSL) no fornecimento de serviços em cadeias de suprimentos. Por meio de uma análise teórica, o estudo propõe quais seriam as principais competências para este segmento. Em uma pesquisa de campo com oito operadores, essas competências são avaliadas na prática. Com a análise, conclui-se haver correlação entre a teoria estudada e a pesquisa de campo. Como contribuição, o estudo apresenta novas competências para estes operadores, sinalizando existir oportunidade para que possam evoluir para serviços mais abrangentes, em que o processo de integração e coordenação de atividades na CS (cadeia de suprimentos) seja o foco.

Palavras chaves: Prestadores de Serviços Logísticos; Cadeia de Suprimentos; Operações logísticas.

This paper discusses the competences that are necessary to 3PL (third party logistics // Logistics Service Provider - LSP) provide services in supply chains. Through a theoretical analysis the study proposes which would be the main competences for this segment. In a field study with eight operators such competences are evaluated in practice, the analysis concludes there is correlation between the studied theory and field research, and new competences are found. With the information from the $3 \mathrm{PL}$ studied, the study indicates there is opportunity for them to develop into more extensive services in the process of integration and coordination of activities in SC (supply chain.

Key-words: 3PL, supply-chain, logistic

\section{INTRODUÇÃO}

Nas últimas duas décadas, os prestadores de serviços logísticos (PSL) estabeleceram-se como organizações capazes de contribuir com os negócios de seus clientes; consolidaram-se na execução dos chamados serviços primários da logística, como armazenagem e transporte; foram incorporando diferentes tipos de serviços a seus negócios; e mais recentemente estão evoluindo para operações 
integradas a cadeia de suprimentos (CS) de seus clientes (VIVALDINI; PIRES, 2010).

Para muitos autores (SAHAY, 2003; WANKE; 2004; SELVIARIDIS; SPRING, 2007; LIEB; LIEB, 2010; VIAYVARGIYA; DEY, 2010) estes provedores não representam mais uma simples terceirização de serviços logísticos, mas sim uma relação de negócio comprometida com o negócio de seu cliente.

As atividades logísticas constituem o principal produto do PSL e, por serem inúmeras, elas tornam-se possibilidades de negócio e uma porta capaz de abrir relacionamentos com potenciais clientes. Portanto, é fundamental a estes provedores entenderem que papel e atividades podem executar no fluxo da CS do cliente, e nele atuar buscando incorporar cada vez mais atividades.

Neste contexto, pode-se entender que a vantagem comercial deste provedor em termos de conquista de novos clientes pode está nos diferentes tipos de atividades ou serviços que executam para a CS de seu cliente. Estas atividades e serviços, combinados com entendimento e conhecimento que possuem a respeito dos desafios e demandas de uma cadeia de suprimento, caracterizam-se como as principais competências necessárias ao PSL para diferenciar-se dos concorrentes. Estas competências podem ser entendidas como a capacidade de atender aos diferentes tipos de serviços, aliando a eles inovação, avanço tecnológico e capacidade de agregar valor ao negócio de seu cliente. Esta definição, especificamente para PSL, esta baseada na posição de Fleury e Fleury (2001) que entende a competência organizacional como a capacidade de combinar, misturar e integrar recursos em produtos e serviços.

Power, Sharafali e Vikram (2007) e Langley e outros (2009) acreditam existir confusão a respeito das competências que diferenciam os PSL, bem como de que os clientes confundem serviço oferecido com serviço requerido, e por isso, encontram dificuldades em avaliar estes operadores quando da sua contratação. Considerando ainda que este segmento tem ganhado espaço no mercado, é intenção deste estudo entender as competências que os diferenciem no atendimento a clientes, contribuindo tanto para o próprio segmento, quanto para as empresas que pensam em contratá-los.

Num primeiro momento, o estudo busca na literatura quais poderiam ser estas competências. Em um segundo, avalia, por meio de uma pesquisa de campo, se estas competências são aplicadas pelos oito PSL pesquisados, bem como observa se outras mais, não identificadas na literatura, podem ser consideradas. Assim, por meio do encontro da teoria com a observação prática, este artigo procura estabelecer novos conhecimentos a respeito dos PSL.

\section{O PRESTADOR DE SERVICOS}

Para definir as principais competências exigidas dos PSL, o estudo teórico discute o entendimento sobre: (1) a terceirização dos serviços logísticos, (2) a importância da prestação de serviços logísticos terceirizados na CS, (3) os fatores de sucesso para este segmento, (4) seu envolvimento na gestão colaborativa da CS, e por fim, baseado na pesquisa obtém-se (5) a classificação das principais competências. 


\subsection{Serviços Logísticos Terceirizados}

Caracterizada pelas diversas transformações organizacionais, a terceirização se consolidou em diversos setores e não foi diferente na prestação de serviços logísticos. Inicialmente, a gestão de atividades logísticas estava mais focada em armazenagem e transporte, sem muita relação com os processos estratégicos da CS na busca de vantagens competitivas.

Segundo Dornier, Ernest, Michel, e Panos (2000) os serviços logísticos se dividem em 4 diferentes tipos: serviços básicos, que não requerem grande coordenação; serviços logísticos contratuais físicos, que permitem a terceirização de alguns dos serviços físicos, enquanto a empresa ainda mantém controle da gestão; serviços logísticos contratuais de gestão, que subcontratam a gestão de um armazém ou frota de transporte existente; e logística contratual integrada, que incorpora serviços físicos e funções gerenciais ao operador logístico.

Segundo Power, Sharafali e Vikram (2007) e Langley e outros (2009) em uma seqüência histórica de 14 anos de pesquisas sobre PSL, consideram que os principais serviços terceirizados com estes agentes são:

- Transporte interno (nacional) e externo (internacional);

- Despacho aduaneiro;

- Armazenagem e administração de estoque;

- Transferências de produtos entre fábricas e reposição de peças e produtos;

- Serviços de cross-docking;

- Serviços de etiquetagem, packing e formação de kits;

- Logística reversa (retorno de defeitos, reparos, produtos);

- Auditoria de frete e pagamentos;

- Planejamento de armazenagem e transporte;

- Serviços e soluções de tecnologia de informação voltada para logística;

- Gestão de transportadoras, de frota e sistemas de monitoramento de frota;

- Serviços de consultoria, projetos e coordenação logística em CS;

- Serviço de atendimento a clientes e sistemas de informações;

- Recepção e processamento de pedidos;

- Quarterização logística (gestão de terceiros que exercem as operações logísticas);

- Transferência de recursos (como locação de empilhadeiras e mão-de-obra);

- Apoio as atividades de marketing.

Também, nessa mesma pesquisa são apontadas as principais razões pela qual as empresas decidem não contratar os PSL. Entre as razões mais freqüentes estão: redução de custo e nível de serviço não realizado - a logística é a competência da empresa, ou é considerada muito importante para ser terceirizada, ou a empresa acredita ter mais competência do que o PSL -, e perda de controle sobre as atividades.

A implementação dos serviços contratados junto a um PSL pode ser considerada difícil. As dificuldades compreendem o entendimento do cliente sobre a necessidade de sua CS, e a inadequada descrição dos serviços e níveis de serviços (SELVIARIDIS; SPRING, 2007).

Segundo Berglund, Laarhoven, Sharman e Wander (1999), há dois direcionadores que conduzem as empresas a terceirizar as atividades logísticas: o tamanho da demanda e o tamanho da cadeia. Isto, combinado com a posição de 
Svensson (2003) de que as empresas estão reduzindo o número de terceiros contratados e concentrando cada vez mais atividades em um mesmo, pode aumentar a dependência da empresa na CS e as chances de ter o PSL com um grupo maior de atividades sendo executado.

A seguir, em uma adaptação dos tópicos sugeridos por diversos autores (JAAFAR; RAFIQ, 2005; VIJAYVARGIYA; DEY, 2010), tem-se um resumo das motivações e razões que levam uma empresa a terceirizar os serviços logísticos, bem como os possíveis benefícios que podem obter:

- Focar esforços em seu próprio negócio e na busca de novos mercados;

- Reduzir os custos logísticos, evitando investimentos em ativos não relacionados ao negócio da empresa;

- Ter uma CS complexa devido a uma base de supridores fragmentada, adicionando valor as operações existentes;

- Flexibilizar e consolidar o processo de expedição;

- Aumento do retorno de produtos;

- Coordenar as atividades logísticas numa visão mais global;

- Melhorar e controlar os níveis dos serviços e das atividades logísticas;

- Ter maior flexibilidade e eficiência nas operações logísticas;

- Ter acesso a novas tecnologias de informação e comunicação (TIC) e conhecimento logístico;

- Ter somente um ponto de contato, fortalecendo a relação com o agente logístico.

O PSL é um instrumento de parceria na CS pelo conhecimento e infraestrutura que possui. Em vez de possuir por completo a capacidade logística total e ter uma grande estrutura organizacional logística, algumas empresas escolhem compartilhar sua capacidade logística com outras empresas ou contratar as atividades logísticas para serem desempenhadas por empresas especializadas em fornecer tais serviços, chamados de terceiros. O grau de terceirização varia e a atividade terceirizada difere muito pela sua complexidade. Assim, o PSL cobre da mais simples atividade até as mais sofisticadas soluções logísticas (STEFANSSON, 2005).

\subsection{A Importância dos Serviços Logísticos Terceirizados na CS}

O PSL está posicionado entre o cliente e os consumidores de seu cliente. Potencialmente tem a função de lidar com a informação do cliente e o feedback do consumidor. As empresas que utilizam o PSL passam a ter nele uma figura chave para o desenvolvimento de sua CS e para o relacionamento com seus clientes (SILVIARIDIS; SPRING, 2007).

Svenson (2003) destaca que a tendência das empresas é subcontratar um maior número de atividades no fluxo outbound (a jusante) e menor no inbound (a montante), mantendo maior dependência nos processos a jusante do que a montante. Dados comprovados na pesquisa de Jaafar e Rafiq (2005) apontam cerca de $4 \%$ das contratações a montante e $52 \%$ a jusante.

Apesar dos serviços mais importantes ainda serem transporte e armazenagem, muitos outros serviços têm sido incorporados pelo PSL no intuito de atender aos clientes, principalmente de fortalecer os serviços e agregar valor à CS de seus clientes. Para Lieb e Bentz (2005), 80\% das empresas afirmam ser o PSL 
parte da sua estratégia na cadeia de suprimentos, bem como $70 \%$ delas consideram positivo o impacto nos custos logísticos e no nível de serviço.

Para Vijayvargiya e Dey (2010), o processo de terceirização logística oferece vantagens e desvantagens. Para eles, a grande desvantagem seria a perda de controle de uma função específica por parte do contratante. Já as vantagens seriam:

- Foco nas forças essenciais - a utilização de PSL permite a empresa contratante focar em competências centrais.

- Oferecer flexibilidade tecnológica - à medida que a tecnologia avança, o PSL tende a atualizar seus recursos, os quais são parte de seu negócio. Já para as empresas contratantes, isso exige investimentos nem sempre disponíveis;

- Outras flexibilidades - Dispor de opções geográficas para diversos serviços que o PSL pode oferecer.

Hilletofth e Hilmola (2010) e Vaidyanathan (2005) relatam que o PSL com conhecimento em CS e relações globais é uma opção estratégica para oferecer soluções inovadoras em logística, no controle de inventário e na administração da demanda, encontrando melhores níveis de alocação, transporte multi-modal, armazenagem, oferta de TIC, cobertura global, e capacidade de atuar na manufatura e serviços da indústria. As empresas tendem a ganhar competitividade com serviços logísticos sob medida.

O Quadro 1, baseado em Power, Sharafali e Vikram (2007), Selviaridis e Spring (2007) e Langley e outros (2009), resume os fatores que vêm favorecendo a utilização dos PSL.

\section{Fatores que favorecem a utilização dos PSL}

Proliferação de novos produtos

Globalização

Maior exigência de Serviços na CS

Menores ciclos de vida (vestuário, eletrônica)

Mercado mais segmentado

Forte pressão por melhoria nos preços

Ênfase das empresas na gestão da CS

Melhoria nos serviços aos clientes

Surgimento de novas tecnologias em logística Inovações tecnológicas em armazenagem e transporte
Soluções em IT

Busca de Integração na CS

Ter relacionamentos mais fechados

Reduzir parceiros nas operações

logísticas

Conhecimento específico sobre uma operação

Segurança nas operações logísticas

Necessidade de soluções em

embalagens

Flexibilidade na execução de serviços

Preparação para flutuações da demanda

Quadro 1 - Fatores que favorecem a utilização dos PSL

Para Figueiredo (2005), a sofisticação dos serviços e das tecnologias oferecidas pelo PSL está atraindo muitas empresas a incluírem mais atividades nos seus escopos de contratação, no intuito de aumentarem o raio de alcance dos potenciais benefícios. Langley e outros (2009) destacam a importância do relacionamento entre PSL e cliente como forma de expandir os serviços. Eles apontam como expectativa dos clientes a necessidade do PSL ser mais dinâmico na oferta de tecnologia e soluções operacionais, tais como recepção de pedidos e rastreabilidade do produto. Nesta linha, Lieb (2008) acredita que haverá expansão na utilização do RFID (Radio Frequency Identification ) por parte dos PSL. 
Nesta linha de necessidades tecnológicas para os PSL, além do RFID, Power, Sharafali e Vikram (2007) apontam:

- Sistema de notificação de embarque;

- Visualização de estoque em tempo real;

- EDI (eletronic data interchange);

- Serviços de voz no picking;

- Portal de relacionamento;

- Internet;

- Comunicação via rádio freqüência;

- Sistemas de integração entre as empresas;

- Informações eletrônicas e sistemas de suporte a decisão (tipo BI - Bussiness inteligence);

- Extranet e intranet;

- Comunicação via satélite;

- WMS (wherehouse management system).

Outro aspecto, lembrado por Lieb (2008), é a abrangência global que o PSL tem atingido, uma vez que a expansão de negócios das grandes empresas leva consigo seus operadores. Essa abrangência exige do PSL muito mais versatilidade na oferta de serviços aduaneiros e sistema de fretes internacionais.

\subsection{Fatores de Sucesso para PSL}

Langley e outros (2009), Power, Sharafali e Vikram (2007) e Selviaridis e Spring (2007) relatam que a intenção do PSL é manter seus serviços e continuar trabalhando como um provedor de soluções logísticas. Entretanto, a tendência dos contratos, entre PSL e clientes, tem sido a de exigir maior cobertura geográfica e mais atividades. Esse cenário é um desafio para eles. No longo prazo, a tendência deste mercado é de prover oportunidades para novas empresas de logística, voltadas a processos mais amplos, focadas na coordenação e na integração das atividades, como um 4PL (Fourth-Party Logistics - Quarteirização Logística).

Para estes mesmos autores o PSL precisa construir novas habilidades para melhorar as relações com a cadeia de negócios em que está inserido, bem como pensar em ações relacionadas com a sustentabilidade. Por outro lado, os clientes também devem evoluir na relação para melhor entender o que realmente querem de seus operadores. Para tanto, os PSL devem considerar sempre novos caminhos e novos serviços para conquistar seus clientes. E para isso devem adotar uma estratégica que permita aplicações em tecnologia da informação e comunicação (TIC) flexível e com padrões abertos para o mercado, facilitando o atendimento de múltiplos clientes, com baixo custo e preparados para estabelecer relacionamento colaborativo com seus clientes. Este, por sua vez, é um desafio dos dois lados, PSL e clientes, com ações que direcionam o compartilhamento de indicadores, idéias, compromissos de longo prazo e modelos que compartilhe riscos e recompensas pela inovação.

O quadro 2 apresenta um resumo dos trabalhos destes autores, com relação as principais ações que podem ser consideradas fatores de sucesso para os PSL. 
\begin{tabular}{l}
\hline \multicolumn{1}{c}{ Fatores de sucesso para PSL } \\
\hline Objetivos comuns e interesses compatíveis com seus clientes \\
Compatibilidade nos sistemas de informação e comunicação \\
Compatibilidade na cultura organizacional e nas rotinas \\
Orientação para o cliente - consumidor \\
Conhecimento especíico em mercados, produtos e processos específicos \\
Estabilidade financeira \\
Troca frequente de informação e comunicação \\
Investimentos e planos conjunto para alcançar objetivos reais \\
Administração e controle do relacionamento com os clientes \\
Ter mecanismos para resolução de conflitos \\
Balancear o poder nas relações \\
Ter habilidade para buscar novas tecnologias \\
Trabalhar compartilhando riscos e resultados \\
Compartilhamento dos custos pelas melhorias ou queda nos níveis de serviços \\
Flexibilidade na oferta de serviços \\
Ter alto suporte administrativo \\
Estar aberto para entender as necessidades de seus clientes
\end{tabular}

Quadro 2 - Fatores de sucesso para PSL

Langley e outros (2009) dizem que o PSL, por meio da incorporação de novas atividades exigidas pelo mercado, tem mudado ao longo dos anos. Este movimento demonstra progresso e caracteriza maturidade dos operadores. No entanto, os clientes pensam em ter no PSL mais habilidade para desenvolver serviços, melhorias no relacionamento, dar mais importância às informações, envolver-se nas regras e conceitos de integração da CS, como também construir expertise em serviços e operações dedicadas. Também, para os autores, o mercado tende a adotar soluções advindas de empresas voltadas à coordenação logística. Isso cria as seguintes expectativas para os PSL:

- Evoluir para um provedor de soluções para a CS;

- Aumentar os serviços terceirizados por intermédio de um maior número de atividades (ampliar serviços aos clientes);

- Melhoria contínua em tecnologia e habilidade para prover serviços necessários;

- Ter foco nas necessidades dos clientes (prover soluções certas, estar envolvido nos planos de integração do cliente e entender o cliente-indústria);

- Estender o relacionamento com o cliente;

- Continuar adquirindo empresas e expandir os negócios;

- Atuar para mercados globais;

- Caminhar para soluções de coordenação logística como 4PL;

- Buscar relacionamentos de longo prazo, baseados em contratos superiores a 2 anos.

Chapman, Soosay e Kandampully (2003) apontam que as organizações logísticas estão redesenhando suas estruturas e relacionamentos para facilitar e melhorar a comunicação de dados, informação e conhecimento, enquanto melhora sua coordenação, tomada de decisão e planejamento. Elas devem, principalmente, sincronizar atividades entre os agentes da CS, com o objetivo de ganhar e integrar conhecimento e operar com TIC, provendo eficiência e produtividade para a cadeia.

A presença de um PSL utilizando TIC pode contribuir para os custos das operações logísticas e favorecer a integração da CS. Esta combinação elevará o PSL a níveis mais altos de responsabilidade na cadeia, como a de um Líder 
Logístico ou a de um 4PL, coordenando outros PSL e trabalhando em soluções para a CS (VAIDYANATHAN, 2005).

Considerando que um PSL é candidato natural a evoluir seus serviços para 4PL, Visser Konrad e Salden (2004) e Hoek (2006) defendem que ele necessita ter estratégias bem definidas para iniciar o processo de transição. Além disso, deve entender bem a importância de investimentos em TIC, para alcançar esse objetivo.

$\mathrm{Na}$ intenção de poder estabelecer um melhor entendimento do papel do 4PL, tem-se a seguir algumas considerações de Visser, Konrad e Salden (2004), e Hoek (2006) a respeito.

Visser, Konrad e Salden (2004):

- O PSL conduz a operação, mas seu cliente controla a estratégia sobre os conceitos básicos que estão sendo utilizados na cadeia de suprimentos. $O$ PSL melhora a operação efetiva da cadeia, mas não se envolve na discussão da estratégia e conceitos logísticos;

- O 4PL aconselha como, espacialmente e funcionalmente, re-configurar a cadeia de suprimentos, para reduzir custos e melhorar os serviços. O 4PL desenvolve conhecimento e competências logísticas e geralmente aconselha, desenha e implementa novas soluções na cadeia de suprimentos;

- Um aspirante a 4PL tem que investir em sua imagem e reputação, especializar-se em certas atividades e setores e achar outros caminhos para revelar sua confiabilidade.

- Hoek (2006):

- Diferentemente do PSL tradicional, 4PL participa na coordenação da cadeia, em vez de simplesmente prover serviços operacionais;

- Ser um 4PL eleva o PSL tradicional para uma posição de coordenador do fluxo de produtos, deixando para trás a restrita posição de operador do movimento físico dos produtos;

- O modelo de PSL exige mais ativos físicos, enquanto que no caso do o 4PL isso não ocorre, pois está mais voltado para a coordenação da cadeia.

Para Langley e outros (2009) o PSL evoluiu seu modelo de negócio para atender as expectativas dos clientes e capturar maior participação no mercado. Os modelos de negócios variam segundo o escopo de serviços oferecidos, a cobertura regional e o grau de colaboração na CS.

$\mathrm{Na}$ intenção de caracterizar os diferentes tipos de PSL este estudo adota a visão estabelecida na pesquisa de Langley e Allen (2005), resumida no quadro 3. Os autores comparam os diferentes modelos de operadores logísticos, facilitando o entendimento a respeito das funções e do processo evolutivo deste segmento, também é possível perceber que atribuem ao 4PL uma ideia de integradores e agentes colaborativos da CS, que estão acima dos PSL e do Líder de provedores de serviço. 


\begin{tabular}{|c|c|c|c|c|}
\hline Serviço Oferecido & Relacionamento & Preço & Modelo Logístico & Atributos Chaves \\
\hline \multirow{6}{*}{$\begin{array}{l}\text { Serviço avançado } \\
\text { (tipo 4PL) }\end{array}$} & \multirow{6}{*}{ Parceria } & \multirow{6}{*}{ Valor baseado } & \multirow{3}{*}{$\begin{array}{c}\text { Cadeia de Suprimentos } \\
\text { Integrada }\end{array}$} & Relacionamento estratégico \\
\hline & & & & $\begin{array}{l}\text { Expertise em gestão da cadeia de } \\
\text { suprimentos }\end{array}$ \\
\hline & & & & \begin{tabular}{|llll}
$\begin{array}{l}\text { Baseado } \\
\text { informação }\end{array}$ & em & conhecimento & e \\
\end{tabular} \\
\hline & & & \multirow{3}{*}{ Gestor Logístico Líder } & Risco e recompensa compartilhado \\
\hline & & & & Vantagem tecnológica \\
\hline & & & & Adaptável, flexível, e colaborativo \\
\hline \multirow{3}{*}{ Lider logístico } & \multirow{3}{*}{ Parceria } & \multirow{3}{*}{$\begin{array}{c}\text { Risco } \\
\text { compartilhado }\end{array}$} & \multirow{3}{*}{ Provedor Logístico Líder } & Administração de projeto e contratos \\
\hline & & & & Único ponto de contato \\
\hline & & & & Integração tecnológica da operação \\
\hline \multirow{2}{*}{ Valor Agregado } & \multirow{2}{*}{ Contratual } & \multirow{2}{*}{ Fixo e variável } & \multirow{2}{*}{ Operador Logístico } & Capacidade de atendimento \\
\hline & & & & Maior abrangência nos serviços \\
\hline \multirow{2}{*}{ Serviços básicos } & \multirow{2}{*}{ Commodite } & \multirow{2}{*}{ Transação } & \multirow{2}{*}{$\begin{array}{c}\text { Provedor de Serviços } \\
\text { Logísticos }\end{array}$} & Foco em redução de custos \\
\hline & & & & Serviços específicos \\
\hline
\end{tabular}

Quadro 3: Características para serviços de PSL (LANGLEY e ALLEN, 2005)

Ratten (2004) coloca que muitas alianças logísticas estão sendo formadas com base nas mudanças tecnológicas, na intenção de melhorar a transmissão de dados e transações. Neste caso, alianças com empresas do setor de tecnologia podem ser necessárias ao PSL.

\subsection{O PSL e a Gestão Colaborativa na Cadeia de Suprimentos}

O contrato de prestação de serviço é a forma mais comum de firmar o relacionamento para serviços terceirizados. No caso dos PSL este contrato é importante e deve abranger: tempo/duração, custo das atividades, descrição dos serviços e atividades, bônus ou pênalti por resultado, definição de responsabilidades e riscos, nível de serviço contratado e indicadores de desempenho. Este último é importante para monitorar, identificar e corrigir ações e falhas nos processos (SELVIARIDIS; SPRING, 2007).

Os indicadores podem ser uma ferramenta de equilíbrio da relação, mas, por mais que as empresas queiram o relacionamento, o objetivo idealizado pode não ser alcançado, não por incompetência, mas por razões internas ou externas às empresas. Na prática, vencer estes obstáculos é muito difícil. Isto indica que o relacionamento pode refletir situações alinhadas e desalinhadas que podem ou não ser remediadas em termos de resultados e desempenho.

Outro aspecto relacionado à terceirização pode estar no fato de que nem sempre o processo de contratação está suportado por indicadores propriamente alinhados com os objetivos das empresas. Supostamente, eles tendem a estar suportados por interesses de quem contrata, ou práticas gerenciais impróprias (LONSDALE; COX, 2000).

Estas práticas impróprias afetam o relacionamento entre as empresas e, conforme apontou a pesquisa de Langley e outros (2009), tem sido preocupação tanto de PSL quanto de seus clientes em encontrar meios que fortaleçam o relacionamento. Esta mesma pesquisa aponta três fatores que contribuem para a relação entre PSL e cliente: abertura, transparência e boa comunicação; relacionamento pessoal além do operacional; e flexibilidade. A visão estabelecida por esta pesquisa é de que através da integração entre PSL e cliente por meio de 
ferramentas tecnológicas é possível melhorarem a relação e caminhar para uma gestão colaborativa entre eles.

Nesta linha, Sing e Power (2009) defendem que empresas interessadas em desenvolver a colaboração necessitam saber de todos os fatores importantes que contribuem para o sucesso dos resultados obtidos com a colaboração. Um exemplo prático dessa colaboração é colocado por Cambra-Fierro e Pólo-Redondo (2008) ao avaliarem o papel dos agentes em relação à demanda - em que os autores defendem que ela deve ser definida como as atividades da cadeia através da qual os fornecedores reconhecem a demanda do cliente, transferindo as informações da demanda do mercado para os fornecedores. Neste caso, a cadeia deve ser adequadamente administrada, o suprimento deve ser bem sincronizado com a demanda de forma que o resultado obtido disso provenha valor para todos na cadeia.

Analogamente com o papel de integração dos PSL na CS, apontado na pesquisa de Langley e outros (2009), em que este provedor se envolve com diferentes agentes da cadeia de seu cliente, este sincronismo que a gestão da demanda exige deve ser entendido por ele e seu cliente como um esforço para a colaboração na cadeia.

Considerando o fato de que os serviços contratados de um PSL geralmente são marcados por prestação de serviços em um prazo mais longo do que simplesmente uma relação transacional, pode-se dizer que isto favorece a relação colaborativa, uma vez que segundo Kanagaretnam, Mestelman, Nainar e Shehata (2010) repetidas interação (que é o caso dos serviços prestados pelo PSL) aumenta a confiança e a reciprocidade entre as empresas, com ou sem transparência. Esta por sua vez, é importante na construção da confiança envolvida nos negócios, tal como, a divisão de responsabilidades e de investimentos.

Também, para Ryu, So e Koo (2009) a confiança só pode ser construída através da experiência entre as empresas no longo prazo, que é a caso das relações dos PSL. Para ele a aproximação operacional influência a confiança, mas não influência o compromisso existente entre as empresas. No entanto, o compromisso é construído sobre fundamentos existente na confiança entre as empresas. Segundo os autores, o desenvolvimento da confiança e do compromisso por meio da interação de duas empresas, como no relacionamento entre PSL e cliente, promove colaboração entre as demais empresas da CS e ajuda a sustentar a colaboração.

Além dessa pressuposta contribuição do PSL a gestão colaborativa, Holweg e Pil (2008) relatam que uma característica comum para resolver muitos problemas existentes na CS (chamado por ele dos "males" da CS) é transferir informações sem atraso entre os parceiros. Neste papel, o PSL tem se mostrado um agente capaz de responder a este serviço, facilitando e provendo visibilidade aos diferentes tipos de informações necessárias a uma cadeia e seus agentes.

\subsection{Fatores de Competitividade para o PSL}

Com base na literatura estudada, este estudo propõe, a seguir, as competências consideradas como diferenciais para PSL.

- Participar da CS do cliente estrategicamente: estar envolvido em desenvolvimentos de produtos, atuar nas diferentes camadas da cadeia de seu cliente, participar de campanhas, etc. 
- Capacidade para atuar na gestão da demanda de seu cliente: a gestão da demanda é um dos pontos mais críticos em CS. Ter visão de como cooperar nos negócios de seu cliente, bem como ter ferramentas que contribuam para isso, ajuda o PSL na conquista de clientes.

- Prestar serviços na intenção de construir um negócio amparado por conceitos colaborativos com seu cliente e todos os agentes da cadeia em que estará envolvido.

- Ter medidas de desempenho focadas nos processos operacionais da CS: atuar internamente e externamente orientado por indicadores que balizem as operações contratadas. Orientar seus contratos e serviços por meio de indicadores previamente negociados.

- Atuar no modelo 4PL ou Líder Logístico (coordenação logística na CS): poder coordenar diversas atividades por meio de diferentes prestadores de serviços.

- Prestar diversas atividades (versatilidade nos tipos de serviços prestados): ter conhecimento, habilidades e estrutura operacional que suporte diversas atividades, podendo com elas oferecer ao cliente a opção de atuar somente com um PSL.

- Dispor de tecnologia de informação e comunicação voltada para a CS do cliente: o volume de informações geradas pelos diferentes tipos de serviços existentes na CS exige do PSL um sistema de dados e comunicação robusto, capaz de suportar todas as interfaces e geração de informações necessárias ao seu negócio e ao negócio de seu cliente.

- Atuar em diferentes regiões, ou seja, ter cobertura geográfica. Quanto maior a abrangência geográfica que o PSL possui, com diferentes pontos de armazenagem e cobertura em diferentes modais, maior são as possibilidades para servir os negócios de seu cliente.

\section{METODOLOGIA}

Esta pesquisa é entendida como um estudo de caso, por se tratar de um estudo especifico em oito empresas, conduzido mediante observações e entrevistas com as próprias empresas, realizadas pelo autor em visitas periódicas entre os anos de 2008 e 2010. Ou seja, seu objetivo é aprofundar o conhecimento sobre as competências dos PSL, que é um tema ainda em desenvolvimento, pelo crescimento observado no mercado e pela abrangência de operações atribuídas a eles. Portanto, o trabalho visa melhor compreender o papel deste provedor, sugerir hipóteses e questões e ajudar no desenvolvimento da teoria a respeito (EISEUHARDT, 1989). A Figura 1, a seguir, apresenta o modelo metodológico adotado para conduzir este estudo.

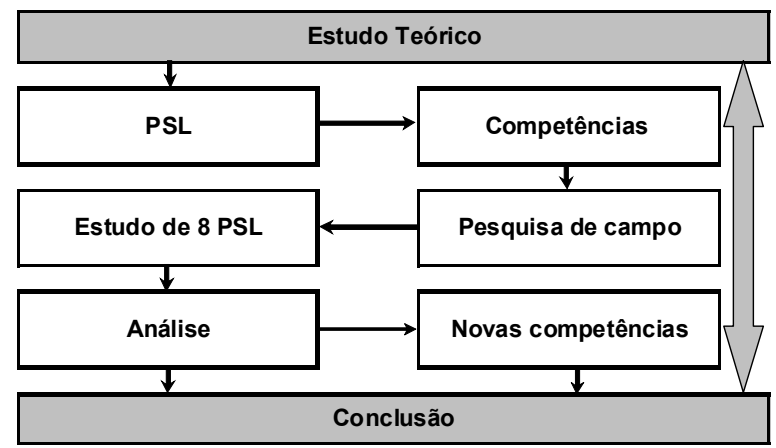

Figura 1 - Organização da pesquisa 
O longo período de pesquisa e interação com as empresas permitiu ao autor melhor entender o negócio de cada uma, bem como ajudou a avaliar o comportamento dessas empresas diante de seus clientes e mercados. Durante a pesquisa, o contato com diversos funcionários esclareceu dúvidas e ajudou a entender as empresas, facilitou a análise entre as competências obtidas na teoria com as observadas nas empresas. Para se chegar a isso, a pesquisa foi organizada segundo sugestão de Miguel (2007) e Eisenhardt (1989), como segue:

A - Análise da literatura: foi feito um estudo sobre a teoria a respeito de Prestadores de serviços logísticos, com a intenção de delimitar o tema e classificar as competências.

B - Planejamento da pesquisa: o interesse do autor pelas empresas deve-se ao fato delas representarem exemplos para o estudo, devido às diferentes características que apresentam, tais como operadores de grande porte e pequeno porte, com muitas atividades e poucas atividades, com foco em transporte e armazenagem, foco mais forte em armazenagem, foco mais forte em transporte e com atuação aduaneira. Isto não implica em afirmar que a escolha represente uma amostra ideal para pesquisa, mas sim que os diferentes tipos permitem ao autor uma melhor análise das competências existentes neste segmento. Também, o fato do autor conhecer as empresas, por muitos anos, facilitou contatos, coleta de dados e informações.

- Coleta de dados, informações e registro: foi realizada mediante entrevistas (guiadas por questionários semi-estruturados) e observações diretas, transcritas pelo autor no decorrer da pesquisa.

No intuito de entender os processos relacionados ao estudo, muitos profissionais foram contatados, observados e entrevistados. O Quadro 4 descreve somente aqueles que participaram diretamente das entrevistas. Estas, por sua vez, tiveram a intenção de obter respostas sobre o que se entedia como diferencial na operação de cada empresa, como atividades executadas que diferem do mercado, o que entendem possuir de vantagens em relação ao mercado e por que, como utilizam a Tecnologia da Informação ( $\mathrm{TI}$ ), o que entendem que seus clientes valorizam, e o que entendem como competências para sua empresa e para as empresas de prestação de serviço logístico. Nesta etapa, o autor teve o cuidado de conduzir as entrevistas no nível de proprietário, presidentes, diretores e gerentes coletando as informações relacionadas a diversas questões exemplificadas acima, e na supervisão e base operacional a intenção foi explorar se de fato as características e competências registradas nas entrevistas eram percebidas na equipe e na própria operação. Neste caso, as observações do autor e conversas com diferentes funcionários foi importante, destacando o fato de que o autor tem experiência profissional e acadêmica de cerca de 15 anos em operações logísticas. 


\begin{tabular}{|c|c|c|c|c|c|c|c|c|c|}
\hline \multicolumn{10}{|c|}{ Empresas } \\
\hline Área & Entrevistado & 1 & 2 & 3 & 4 & 5 & 6 & 7 & 8 \\
\hline \multirow{3}{*}{ Staff } & Proprietários & 1 & & 1 & & 1 & 1 & 1 & 1 \\
\hline & Presidentes/Diretores & & 2 & 1 & 2 & & & & \\
\hline & Gerentes Comercial & & 1 & & 1 & 1 & & & \\
\hline \multirow{2}{*}{$\begin{array}{c}\text { Armazéns e Linhas } \\
\text { Operacionais }\end{array}$} & Gerentes & 1 & 1 & 1 & 1 & & & 1 & \\
\hline & Supervisores & & 2 & 1 & & & 1 & 1 & 1 \\
\hline \multirow{3}{*}{ Transporte } & Gerentes & 1 & 1 & 1 & 1 & & 1 & & \\
\hline & Supervisores & 1 & 2 & & 1 & & 1 & & 1 \\
\hline & Chefes oficina & & 1 & 1 & 1 & & 1 & 1 & \\
\hline \multirow{2}{*}{$\begin{array}{c}\text { Pontos de serviços } \\
\text { externos }\end{array}$} & Responsável & & 3 & 1 & 1 & 2 & 1 & 1 & 1 \\
\hline & & & & & & & & & \\
\hline \multirow{2}{*}{$\begin{array}{c}\text { RH/Adm. } \\
\text { Pessoal/Treinamento }\end{array}$} & Gerente & & 1 & & 1 & & & & \\
\hline & Supervisor & & 1 & 1 & & & 1 & 1 & 1 \\
\hline \multirow{2}{*}{ Informática } & Responsável Interno & & 1 & 1 & 1 & & & 1 & \\
\hline & Terceirizado & & & & & 1 & 1 & & 1 \\
\hline \multirow{2}{*}{ Adm. Operacional } & Gerente & 1 & 1 & & 1 & & & & \\
\hline & Supervisor & & 1 & 1 & 1 & & 1 & 1 & 1 \\
\hline Total & 74 & 5 & 18 & 10 & 12 & 5 & 9 & 8 & 7 \\
\hline
\end{tabular}

- Filtro de informações: após obter diversas informações e dados, com foco no objetivo da pesquisa (competências na condução e operação de seus negócios), o autor extraiu as informações relevantes e buscou outras entrevistas com executivos e funcionários das empresas na intenção de obter novos esclarecimentos. Inclusive, nesta etapa, os executivos das empresas foram questionados, quando conheciam algum dos outros PSL participantes da pesquisa, sobre as competências que entendiam se destacar neles.

C - Análise do conteúdo e conclusões: buscou-se realizar a análise e o cruzamento dos dados e das informações para esclarecer divergências e dúvidas, retornando as empresas pesquisadas, quando necessário, para discussão dos resultados e entendimento das discordâncias junto aos entrevistados. Nesta etapa, a intenção foi evitar conclusões influenciadas pela teoria ou por deduções pré-estabelecidas pelo autor.

\section{ESTUDO DE CAMPO}

Este tópico considera três partes:

- Descrição e considerações a respeito das empresas estudadas;

- Relação das empresas com as competências estudadas;

- Análise sobre a existência de novas competências observada nos casos estudados. 


\subsection{Empresas Estudadas}

As oito empresas analisadas são PSL que atuam no mercado há mais de 10 anos. Quatro delas passaram pelos processos de incremento de atividades ao longo dos anos, comprovando o que a teoria aponta como evolução deste segmento. Elas foram escolhidas por serem diferentes na origem, no tamanho, no faturamento e nas características operacionais e comerciais.

As empresas, cujos nomes são aqui omitidos, podem ser caracterizadas segundo a descrição a seguir:

- Empresa 1 (YB)- Empresa nacional situada no estado de São Paulo, com cerca de 50 funcionários, e há 12 anos atua no mercado logístico. Apesar de ter seu negócio voltado para despacho aéreo, nos últimos quatro anos têm ampliado seus serviços e operações, aproveitando a estrutura existente e o relacionamento com os clientes. Para apoiar suas operações, possui frota própria dedicada a transporte de produtos secos e frios, um galpão de armazenagem na cidade de São Paulo e operadores contratados em todas as capitais dos estados no Brasil.

Ela demonstrou características interessantes, como o relacionamento e a disposição em investir em ativos para servir aos clientes. No entanto, apresenta deficiência nos quesitos relacionados à formação e gerenciamento das informações e atuação com visão na demanda existente na cadeia.

Pode ser caracterizado como um Operador logístico pela capacidade que tem em atender seus clientes, e pelo fato de estar desenvolvendo e criando novos serviços nas redes em que atua.

- Empresa $2(\mathrm{RH})$ - Multinacional Norte Americana, especializada em operações dedicadas, com filiais nos EUA, Canadá e em alguns países da América Latina. No Brasil, opera há 25 anos, com cinco centros de distribuição, 430 funcionários, frota própria especializada no transporte frio e uma operação voltada ao segmento de food-service. Na avaliação do autor a empresa pode ser caracterizada como um prestador de serviços logístico integrado à CS de seu cliente, sendo um misto de 4PL pelo tipo de gestão e de provedor logístico líder pelo tipo de operação que administra e ativos que possui. Provavelmente, isto ocorre pela amplitude do processo operacional executado para seus clientes, característico do que foi discutido na teoria.

Realizam muitas atividades na cadeia, tais como:

- Gestões, sendo elas: dos pedidos de venda, dos fornecedores da primeira camada (planejamento e estoque), do estoque de venda, das informações de venda e abastecimento;

- Todos os processos relacionados à armazenagem, controle de qualidade, transporte, entregas dedicadas etc.;

- Trabalham internamente com a imagem e os negócios de seus clientes, por meio de atendimento e linguagem personalizada;

- Indicadores de desempenho bem desenvolvidos baseados no negócio do cliente, tais como indicadores de confiabilidade e disponibilidade de produtos entregues no ponto de venda, ruptura de estoque nos centros de distribuição e nos fornecedores, atrasos nas entregas, auditorias de qualidade e de processos, desempenho de frota, produtividade das operações por funcionário, veículo etc. 
Uma forte característica deste PSL é sua gestão de informações na cadeia, não só pelo fato de estar voltado para seus clientes, mas por estar bem alinhado internamente com seus objetivos. Isto caracteriza uma força marcante do processo de integração, que é a gestão da TIC.

- Empresa 3 (PS) - Empresa nacional com administração familiar, há 35 anos no mercado, 500 funcionários, com 12 filiais espalhadas pelo Brasil, atuando com grandes clientes de diferentes segmentos como Kraft-Foods, Sara-Lee, BSG-Continental, Parmalat e outros. Operam com transporte, armazenagem, serviços de montagem e packing, manutenção e terceirização de mão-deobra. Apesar da estrutura e diferentes atividades que executa o autor não entende que este PSL atue de forma integrada à CS de seus clientes, sendo muito mais um prestador de diversas atividades para diferentes clientes.

Apesar de ser forte na execução de atividades diversas (principalmente de montagens de kits) é entendido como um Operador logístico com abrangência em serviços dedicados.

- Empresa 4 (CC)- Grande cooperativa nacional no segmento de transporte que ao longo dos seus 20 anos foi se profissionalizando e incorporando operações em grandes clientes. Possui 40 pontos de apoio em todo Brasil, 300 funcionários fixos, filiais com armazenagem nos estados de São Paulo, Rio de Janeiro e Paraná, e terminal de container em Santa Catarina. Apesar de seu foco principal de negócio ser o transporte, possui também armazenagem e operações dedicadas, atuando com clientes como Sadia, Perdigão, Danone, Brasken, Nestlé, Suzano Petroquímica, Firestone etc. Trata-se de uma empresa bem estruturada nas suas instalações e na administração, o que a ajuda na captação de serviços, principalmente de transporte.

Nesta empresa, dois fatores foram marcantes na pesquisa: um, por ser uma cooperativa e ter que atuar na gestão dos cooperados, tanto quanto na dos clientes, e outro, por ter forte característica de um grande transportador. $\mathrm{O}$ fato de possuir grandes clientes poderia facilitar uma atuação mais integrada na CS, no entanto, a distância de ações voltadas à gestão das informações, da demanda e a iniciativa comercial de buscar novas atividades prejudica sua evolução para esta atribuição. Portanto, caracteriza-se como um Operador logístico pelos grandes contratos que possui e por, apesar de forte em transporte, também atuar com armazenagem.

- Empresa 5 (LC) - É uma empresa voltada a operações aduaneiras, atuando no apoio a muitos grandes clientes, como Arcor, Cabot e Flint-ink. Seu trabalho consiste não só na gestão dos processos de importação e exportação, mas em soluções de estocagem e transporte para os produtos de seus clientes. Possui 20 anos de vida, uma sede administrativa na cidade de São Paulo e 70 funcionários espalhados pelos clientes. Opera num estilo 4PL, com foco em exportação e importação, sem ter uma estrutura física própria, administrando os terceiros envolvidos diretamente neste tipo de operação. Este PSL é um operador bem focado em operações aduaneiras, possui bom conhecimento teórico do processo de integração, mas com pouca ação prática na cadeia de seus clientes. Atua à medida que é requisitado, executando operações com começo e fim, raramente são permanentes. $O$ fato de não apresentar estrutura física operacional e tampouco ter conhecimento prático das operações prejudica uma atuação mais abrangente 
no mercado. Por outro lado, destaca-se pelo relacionamento, por estar bem focado nos clientes e por ter suas relações bem fundamentadas na confiança.

- Empresa 6 (PL) - Com foco voltado para atuação em processos de transferências de cargas para seus clientes, na maioria grandes corporações no Brasil, especializou-se em formatar operações dedicadas, com veículos específicos e voltados para operação contratada.

Atua junto a empresas de construção de veículos desenvolvendo modelos diferenciados que possam atender seus clientes. Isto é um diferencial importante, pois costuma propor as soluções e investir no projeto mesmo sem haver compartilhamento de investimentos.

Portanto, pode-se dizer que tem como ponte forte sua versatilidade em criar projetos e idéias para seus clientes, trabalha muito bem integrado com o negócio e com a cadeia de seu cliente, por ter clara a visão que seu serviço deve se adequar e prover solução a seus clientes. Também tem uma postura mais agressiva comercialmente em relação a maioria das demais empresas pesquisadas, atua facilmente com planilha de custos aberta e consegue negociar margens que sustentam seu negócio. Também, tem expandido sua atuação em processos de distribuição urbana (cargas fracionadas), em que mantém a mesma postura comercial e aberta. Com esta ação tem expandido seus clientes, porém tem aumentado seus pontos de atuação, exigindo novos profissionais e postura diferenciada para atuar com sua equipe. Nestas operações tem entrado com uma inovação para regiões mais distantes da base de distribuição de seus clientes: tem feito pontos de apoio onde pode preparar cargas, fracionar, fazer cross-docking para depois entregar ao ponto de venda.

Devido a sua característica comercial e parceria que desenvolve com seus clientes, apesar de atuar apenas com transporte, tem características de um Operador logístico e a medida que vai ampliando seus contratos e negócios tenderá a ser um Provedor líder.

- Empresa 7 (SF) - Concentra seus negócios em serviços de armazenagem. Possui boa infra-estrutura localizada em diferentes pontos. Atua com foco bem definido: Prestar serviços de armazenagem geral, picking de produtos, carregamento, cross-docking, packing e embalagem. Possui uma área de transporte e um número de veículos utilizados em operações dedicadas a grandes clientes, mas esta operação esta voltada apenas para seus clientes e para processos de transferência de produtos entre fábrica e armazenagem e não distribuição.

Operacionalmente procura se adequar ao negócio de seu cliente, restringindo-se a operações de armazém, não demonstra disposição em avançar para distribuição e transporte. Apesar desta restrição, é bem abrangente em serviços de armazenagem, além de estar pulverizando seus armazéns, o que favorece negociações para operações com o mesmo cliente em diferentes pontos. Desta forma, é uma empresa bem definida como um Operador Logístico.

- Empresa $8(\mathrm{KL})$ - Também atua em serviços de armazenagem, porém seu foco esta em guarda de produtos semi-acabados, que ainda irão ser utilizadas pelas fábricas, servindo como 'buffer' para seus clientes. É uma empresa bem integrada com os clientes que atende, geralmente, grandes fabricantes no segmento de cervejas e refrigerantes, e costuma fechar os serviços englobando retirada de produto nos fabricantes, estocagem e abastecimento 
de linha. Monta seus armazéns próximo de seus clientes, e a medida que o volume de operação cresce, expande ou loca novos armazéns. Comercialmente são bem versáteis, e conseguem se adequar rapidamente a demandas inesperadas de seus clientes.

Concentra suas operações na região de Campinas-SP, onde seus clientes estão instalados, com base de apoio em Santos-SP por conta das importações que chegam pelos portos. Com estas características ele pode ser entendido como um Operador logístico.

\subsection{Relação das Competências com as Empresas Estudadas}

O Quadro 5, a seguir, apresenta a relação entre as competências observadas no estudo de campo com as sugeridas pela literatura, com base na análise feita sobre o levantamento de dados obtido na pesquisa e nas observações do autor. Numa análise mais geral sobre o processo de avaliação das oito empresas, algumas considerações podem ser feitas:

- Quanto à gestão colaborativa entre PSL e seus clientes pode-se afirmar que a maioria deles mantém relacionamentos, contratos e operações que sinalizam um importante passo para a consolidação deste conceito. Entretanto, no que tange a participação e integração percebe-se haver pouca sintonia entre os PSL estudados e seus clientes, como haver entre eles melhor definição do papel e do valor das atividades executadas na cadeia, maior sintonia na troca de informação, e melhor percepção do quanto a qualidade das atividades contratadas contribui para o resultado final do próprio cliente, e não somente a contratação ou execução de uma atividade. Com esta posição pode-se concluir que este conceito, favorecido pela integração e pelo apoio em TIC, mesmo nas empresas que possuem capacidade e infra-estrutura técnica para isto, ainda não evoluiu. Ela apenas foi mais evidenciada no caso da empresa $2(\mathrm{RH})$, que notadamente tem uma relação mais fundamentada nos conceitos colaborativos, provavelmente por ser a que mais longo tempo atua com seu principal cliente, conseguindo por isso, estabelecer confiança e compromisso nas ações, operações e no compartilhamento de investimentos.

- Todos os PSL sinalizaram intenção de executar mais tarefas, ampliando o portifólio de atividades como forma de melhoria dos negócios. Entretanto, não é percebida uma relação direta disso com a possibilidade de integração dos processos na CS de seus clientes. Todos evidenciam a pretensão de aumentar clientes através das atividades que já executam, e não de aumentar as atividades na cadeia de seu cliente para seu cliente e seus agentes. Mesmo nas maiores empresas, com uma gestão mais profissionalizada e preparada, não foi evidenciado estratégias nesta direção;

- É consenso atribuírem aos clientes à falta de iniciativa na expansão de atividades, bem como na construção de um relacionamento mais aberto. Dizem que o cliente busca preço e execução, não gestão e resultados. Por isso, pode-se dizer que o conceito de integração e trabalho dedicado, por meio do PSL, torna-se apenas teoria e, por outro lado, sinaliza o quanto os clientes, gestores da cadeia, também necessitam evoluir nesta questão.

- A atuação do PSL com os agentes de segunda camada da cadeia não foi observado, ou seja, para o autor percebe-se que os PSL estudados não 
procuram explorar os demais agentes da cadeia, exceto a empresa 1 (YB) que tem esta característica ao atuar com alguns agentes pertencentes a cadeia de seus clientes.

- Quanto à relação das empresas com medidas de desempenho e o balizamento delas com seus clientes, percebeu-se poucos serviços contratados com base em indicadores, bem como foi observado raros exemplos em que são balizados ou auditados por resultados da operação com seu cliente, porém a maioria deles possuem indicadores internos, medindo principalmente produtividade de funcionários, capacidade ou ociosidade operacional, e outros indicadores relacionado a custos operacionais. Na empresa $2(\mathrm{RH})$, onde é percebido maior integração com o cliente, foi observado uma gestão balizada por indicadores medindo o desempenho interno e externo. Por sua vez, a empresa 3 (PS) relatou um exemplo de contrato em que o valor do serviço esta atrelado ao quanto seus serviços influenciam nos indicadores de seu cliente. Esta característica, particularmente nesta pesquisa, fortalece a ideia de que uma gestão orientada por indicadores de desempenho favorece a integração na CS. 


\begin{tabular}{|c|c|c|c|c|}
\hline Competências & Empresa 1 (YB) & Empresa 2 (RH) & Empresa 3 (PS) & Empresa 4 (CC) \\
\hline Participação na CS & $\begin{array}{l}\text { Limita-se a prestar serviços } \\
\text { contratados pelos clientes }\end{array}$ & $\begin{array}{c}\text { Atuação bem envolvida na CS } \\
\text { do cliente, tanto a montante } \\
\text { quanto a jusante }\end{array}$ & $\begin{array}{c}\text { Na maioria dos clientes } \\
\text { atende somente serviços } \\
\text { contratados, em um atua com } \\
\text { mais atividades na CS }\end{array}$ & $\begin{array}{c}\text { Apesar de possuir grandes } \\
\text { contratos, esta restrita a } \\
\text { serviços contratados pelos } \\
\text { clientes }\end{array}$ \\
\hline Gestão da Demanda & $\begin{array}{c}\text { Não atua, sem conhecimento } \\
\text { e tecnologia para esta } \\
\text { operação }\end{array}$ & $\begin{array}{c}\text { Tem tencologia, conhecimento } \\
\text { e já atua com esta } \\
\text { responsabilidade }\end{array}$ & $\begin{array}{c}\text { Não atua, pouco } \\
\text { conhecimento e tecnologia } \\
\text { insuficiente para esta operaçã }\end{array}$ & $\begin{array}{l}\text { Não atua, tem conhecimento, } \\
\text { mas não tem tecnologia para } \\
\text { esta operação }\end{array}$ \\
\hline $\begin{array}{l}\text { Conceitos } \\
\text { colaborativos }\end{array}$ & $\begin{array}{c}\text { Bem desenvolvido, consegue } \\
\text { compartilhar } \\
\text { responsabilidades, riscos e } \\
\text { resultados com seus clientes }\end{array}$ & $\begin{array}{c}\text { É característica de suas } \\
\text { operações esta postura, } \\
\text { conhece e difunde bem esta } \\
\text { prática com os clientes }\end{array}$ & $\begin{array}{c}\text { Demonstra estar evoluindo na } \\
\text { direção destes conceitos, mas } \\
\text { ainda não fortaleceu esta } \\
\text { cultura na organização }\end{array}$ & $\begin{array}{l}\text { Possui grandes operações } \\
\text { amparadas em contratos. } \\
\text { Internamente domina os } \\
\text { conceitos, mas falta } \\
\text { reciprocidade do lado dos } \\
\text { clientes. }\end{array}$ \\
\hline $\begin{array}{l}\text { Medidas de } \\
\text { desempenho }\end{array}$ & $\begin{array}{l}\text { Não estão bem definidas, e } \\
\text { não utiliza com clientes }\end{array}$ & $\begin{array}{c}\text { Bem estabelecidos, tanto } \\
\text { interno quanto externo. } \\
\text { Orientam-se e negociam por } \\
\text { eles }\end{array}$ & $\begin{array}{l}\text { Ainda em desenvolvimento, } \\
\text { com foco interno e sem } \\
\text { relação comercial }\end{array}$ & $\begin{array}{l}\text { Bem estabelecidos } \\
\text { internamente, com clientes } \\
\text { somente quando contratado }\end{array}$ \\
\hline Modelo 4PL & $\begin{array}{c}\text { Não possui nem estrutura nem } \\
\text { tecnologia para atuar neste } \\
\text { modelo }\end{array}$ & $\begin{array}{c}\text { Possui estrutura, tecnologia e } \\
\text { conhecimento para atuar, } \\
\text { porém não atua }\end{array}$ & $\begin{array}{c}\text { Possui estrutura, mas não } \\
\text { tem tecnologia e } \\
\text { conhecimento deste modelo } \\
\text { de gestão }\end{array}$ & $\begin{array}{c}\text { Possui estrutura, tecnologia e } \\
\text { conhecimento, porém tem } \\
\text { problemas interno por ser uma } \\
\text { cooperativa }\end{array}$ \\
\hline Diversas atividades & $\begin{array}{c}\text { Esta mais focado em } \\
\text { transporte aério e transporte } \\
\text { rodoviário local }\end{array}$ & $\begin{array}{c}\text { Executada diversas atividades } \\
\text { para um grande cliente, porém } \\
\text { não explora esta capacidade }\end{array}$ & $\begin{array}{c}\text { Executada diversas e } \\
\text { diferentes atividades, tendo } \\
\text { boa estrutura para isso }\end{array}$ & $\begin{array}{c}\text { Mais focado em transporte } \\
\text { rodoviário, apesar de possuir } \\
\text { ao infra-estrutura para outras } \\
\text { atividades }\end{array}$ \\
\hline $\begin{array}{l}\text { Tecnologia de } \\
\text { informação e } \\
\text { comunicação }\end{array}$ & $\begin{array}{l}\text { Estrutura tecnologica fraca } \\
\text { para maior abrangência no } \\
\text { mercado }\end{array}$ & $\begin{array}{l}\text { Forte estrutura tecnologica, } \\
\text { capaz de atender diversos e } \\
\text { diferentes clientes }\end{array}$ & $\begin{array}{c}\text { Tecnologia de informação e } \\
\text { comunicação restrita as } \\
\text { operações interna }\end{array}$ & $\begin{array}{c}\text { Tecnologia de informação e } \\
\text { comunicação restrita as } \\
\text { operações interna }\end{array}$ \\
\hline Cobertura geográfica & Local & Nacional e internacional & Nacional & Nacional e internacional \\
\hline Competências & Empresa 5 (LC) & Empresa 6 (PL) & Empresa 7 (SF) & Empresa 8 (KL) \\
\hline Participação na CS & $\begin{array}{c}\text { Restrita a prestação de } \\
\text { serviços contratados pelos } \\
\text { clientes, apesar de ter bom } \\
\text { conhecimento da gestão em } \\
\text { CS }\end{array}$ & \begin{tabular}{|c} 
Seus contratos e negócios \\
ainda estão limitados, mas \\
tem conhecimento e tem \\
ampliado a participação na CS \\
de seus clientes
\end{tabular} & \begin{tabular}{|c|} 
Limitados a serviços \\
contratados, apesar de serem \\
diversos não tem se preparado \\
para atuar de forma mais \\
ampla na CS
\end{tabular} & $\begin{array}{l}\text { Limitado a prestar os serviços } \\
\text { para o qual tem estrutura, } \\
\text { atende as solicitações de } \\
\text { seus clientes apenas }\end{array}$ \\
\hline Gestão da Demanda & $\begin{array}{l}\text { Não atua, tem conhecimento, } \\
\text { mas não tem tecnologia para } \\
\text { esta operação }\end{array}$ & $\begin{array}{c}\text { Ainda não tem infra-estrutura e } \\
\text { equipe preparada para atuar } \\
\text { neste tipo de gestão }\end{array}$ & $\begin{array}{c}\text { Não esta preparado para } \\
\text { atender seus clientes neste } \\
\text { quesito }\end{array}$ & $\begin{array}{l}\text { Não tem estrutura para atuar } \\
\text { neste tipo de serviço, apesar } \\
\text { de estar bem alinhado com } \\
\text { abastecimento de linha de } \\
\text { seus clientes }\end{array}$ \\
\hline $\begin{array}{l}\text { Conceitos } \\
\text { colaborativos }\end{array}$ & $\begin{array}{l}\text { Bem alinhado com seus } \\
\text { clientes nestes conceitos }\end{array}$ & $\begin{array}{c}\text { Possui fortes características } \\
\text { com estes conceitos. Isto tem } \\
\text { ajudado a ampliar seus } \\
\text { negócios }\end{array}$ & $\begin{array}{c}\text { Atua de forma colaborativa e } \\
\text { bem envolvido com seus } \\
\text { clientes, mas sempre restrito } \\
\text { aos serviços que presta }\end{array}$ & $\begin{array}{l}\text { Atua bem alinhado com seus } \\
\text { clientes, mas se restringe as } \\
\text { atividades contratadas }\end{array}$ \\
\hline $\begin{array}{l}\text { Medidas de } \\
\text { desempenho }\end{array}$ & $\begin{array}{c}\text { Não possui indicadores que } \\
\text { balize o negócio da empresa. } \\
\text { Porém cada negócio } \\
\text { contratado pelo cliente tem } \\
\text { metas pré-estabelecidas }\end{array}$ & $\begin{array}{l}\text { Tem bons indicadores interno, } \\
\text { nos externos segue o que foi } \\
\text { contratado com seus clientes }\end{array}$ & $\begin{array}{c}\text { Acompanha sua performance } \\
\text { interna, e consegue alinhar } \\
\text { bem os indicadores de seus } \\
\text { clientes a seu negócio }\end{array}$ & $\begin{array}{l}\text { Precisa consolidar melhor } \\
\text { seus indicadores, não tem } \\
\text { rotina estabelecida nem } \\
\text { internamente nem com os } \\
\text { clientes }\end{array}$ \\
\hline Modelo 4PL & $\begin{array}{l}\text { Sua gestão é bem focada no } \\
\text { modelo } 4 \mathrm{PL}, \text { porém não } \\
\text { possui estrutura e tecnologia } \\
\text { para grandes operações }\end{array}$ & $\begin{array}{c}\text { Apesar de apresentar bons } \\
\text { conceitos e uma postura pró- } \\
\text { ativa, não possui estrutura } \\
\text { técnológica e profissional para } \\
\text { esse modelo }\end{array}$ & $\begin{array}{c}\text { Além da visão restrita para } \\
\text { este modelo, falta estrutura } \\
\text { tecnológica e conhecimento } \\
\text { em gestão de frotas. }\end{array}$ & $\begin{array}{c}\text { Tem bem estabelecida a visãd } \\
\text { para o modelo, porém não tem } \\
\text { estrutura e equipe para } \\
\text { praticar o modelo }\end{array}$ \\
\hline Diversas atividades & $\begin{array}{c}\text { Focado em atividades } \\
\text { aduaneiras }\end{array}$ & $\begin{array}{c}\text { Concentra-se fortemente em } \\
\text { atividades de transporte, nos } \\
\text { últimos } 3 \text { anos tem expandido } \\
\text { para operações de armazém }\end{array}$ & \begin{tabular}{|} 
Executa diferentes atividades \\
em seus armazéns, o que é \\
seu ponto forte, também faz \\
distribuição varejista e \\
transferência entre fábricas
\end{tabular} & $\begin{array}{c}\text { Focado mais em atividades de } \\
\text { armazém, conjugado com } \\
\text { abastecimento das linhas de } \\
\text { seus clientes }\end{array}$ \\
\hline $\begin{array}{l}\text { Tecnologia de } \\
\text { informação e } \\
\text { comunicação }\end{array}$ & $\begin{array}{c}\text { Tecnologia focada nos } \\
\text { negócios aduaneiros, pouco } \\
\text { abrangente para outras } \\
\text { operações }\end{array}$ & $\begin{array}{c}\text { Possui tecnologia voltada para } \\
\text { seus negócios em transporte, } \\
\text { para outras atividades tem } \\
\text { deficiências }\end{array}$ & $\begin{array}{c}\text { Bem estruturado para suas } \\
\text { operações de armazenagem, } \\
\text { para demais operações não }\end{array}$ & $\begin{array}{c}\text { Possui o necessário para } \\
\text { operações de armazém, mas } \\
\text { pouca integração com seus } \\
\text { clientes }\end{array}$ \\
\hline Cobertura geográfica & Local & Nacional & Local & Local \\
\hline
\end{tabular}

Quadro 5 - Avaliação de competências em PSL 


\subsection{Proposição de Novas Competências}

Além da comparação, baseada na literatura, o autor, através das observações na pesquisa de campo, aponta os seguintes fatores que se caracterizam como competências no modelo de gestão do PSL e podem contribuir para que ele melhore seu negócio no mercado:

- Ter estrutura física, operacional e tecnológica capaz de atender a diversos clientes: estrutura operacional combinando transporte, armazém e tecnologia contribuem para a conquista de clientes. A literatura aborda o tema, mas não da ênfase a necessidade de possuir uma estrutura física capaz de atender a diferentes tipos de serviços e clientes.

- Ter foco no segmento que atua, especializando-se em diversas atividades na CS: orientar estrutura e operação para um segmento ajuda na especialização e contribui para atuar de forma mais focada na CS dos clientes. A literatura aborda diferentes tarefas e atuação em segmentos específicos como forma de demonstrar especialização, mas não são tão explorados os tipos de operação que poderiam compor os negócios na cadeia dos clientes. Por exemplo, atuar com transporte e armazenagem, combinado com processos que concilie operações tanto no lado montante quanto jusante da cadeia.

- Concentrar-se em grandes clientes e atuar de forma integrada ao negócio do cliente: dedicação e especialização na CS de poucos clientes podem contribuir para a abrangência de atividades e negócios nas diversas camadas da cadeia. Geralmente, tem-se o entendimento de que com quanto mais clientes o PSL operar melhor será para seus negócios. O observado é que quanto mais focado num mesmo cliente maior é seu envolvimento com as diferentes atividades na CS. Quanto mais abrangente é a rede de cliente menor será o foco nos processos de integração e maior é a concentração na execução de uma mesma atividade.

- Investir com o objetivo de atender e ampliar os negócios com os clientes com quem já atua: demonstrar interesse pelo cliente e propor a ele soluções a partir de investimentos direcionados para o negócio dele ajuda na expansão dos negócios. Principalmente em momentos em que o mercado aumenta a demanda.

\section{CONCLUSÃO}

O estudo, por meio da literatura a respeito, compara os conceitos que fundamentam as competências de provedores logísticos com oito empresas que atuam neste segmento. Conseqüentemente, pode-se dizer que existe coerência entre o que se obteve da teoria e o que se encontrou na prática. Portanto, o objetivo deste estudo, de entender que fatores podem ser considerados como competência para o prestação de serviços logísticos, e se é possível identificá-los nos PSL, bem como se novas competências foram percebidas, foi alcançado. É claro, que pela amplitude do tema abordado, esse estudo não tem a pretensão de atingir ou esclarecer todas as competências relacionadas aos negócios dos PSL, mas sim contribuir com a literatura para o melhor entendimento desse segmento e do próprio tema. 
A caracterização dos PSL estudados, em relação a teoria, sinaliza existir oportunidade para que possam evoluir para serviços mais abrangentes, em que o processo de integração e coordenação de atividades na CS seja o foco ou que possam executar parte destes trabalhos. Esta oportunidade tanto pode ser para o PSL quanto para seu cliente, uma vez que a iniciativa só de um lado pode não construir este caminho. Isto é evidenciado apenas na empresa $2(\mathrm{RH})$ que é identificado como um provedor avançado, devidamente integrado a cadeia de seus clientes, coordenando diversas operações e gerenciando diversos agentes, inclusive outros PSL.

Como descrito no quadro 5 é possível observar que muitas das competências são atendidas ou entendidas pelos PSL. Isto se deve a característica do negócio em que o PSL esta inserido, ou mesmo ao posicionamento que ele decide ter no mercado. Este é o caso da empresa 5 (LC), cujo negócio esta bem definido e focado em operações aduaneiras. Portanto, apesar de demonstrar profundo conhecimento das competências necessárias para PSL, ela não têm intenção nem foco em ampliar seus negócios. Por outro lado, na maioria das demais empresas, percebe-se a disposição em ampliar serviços e ganhar espaço nos clientes com quem já atuam e no mercado. Neste caso, entender as competências necessárias para isso pode ajudar o PSL nesta direção.

Como contribuição para estudos futuros, aspectos relacionados a gestão colaborativa existente entre PSL e seus clientes pode ser melhor explorado, uma vez que a observação destes aspectos em apenas 8 empresas não é suficiente para conclusões a respeito. Este estudo, neste tema especificamente, apenas sinaliza a importância das empresas entenderem este modelo de gestão e que é uma competência fundamental para atuar de forma integrada com seus clientes. Também, pode-se estudar o papel da empresa foco neste modelo, uma vez que essa sim é entendida por diversos autores (SAHAY, 2003; RYU, KOO, 2009; SINGH, POWER, 2009) como a grande condutora do processo de integração em CS.

De forma geral, os principais pontos obtidos deste estudo foram:

- Identificar nas empresas estudadas o tipo de PSL que representam e o estágio em que estão, comparando-as com as propostas obtidas na literatura, e sintetizando suas competências. Essas foram selecionadas da literatura como diferenciais para estes provedores, não sendo apresentado pelo estudo características básicas já presentes e de domínio da maioria dos provedores, como por exemplo, trabalhar com armazenagem e distribuição. Por sua vez, como relatado no quadro 5 , são apresentadas para cada empresa suas competências, podendo ser observado que muitas não foram identificadas, sinalizando as oportunidades que estes provedores possuem.

- A partir das observações e análise sobre as competências presentes ou não nas empresas, o autor teve a oportunidade de levantar novas competências que não foram observadas na literatura.

- Através dos dados e análise é possível concluir ser difícil encontrar um PSL completo, capaz de atender a todas as competências observadas (tanto na literatura quanto as obtidas na pesquisa).

- Foi percebido existir oportunidades para os PSL melhorem sua capacidade operacional e avançarem para modelos de gestão mais completos, conforme apresentado no texto. Entretanto, é importante ressaltar que muitos PSL preferem se posicionar num nicho de mercado e atividades por opção comercial e continuar como estão. 
A ideia de um PSL consciente de seu papel como agente da CS, com ação direta na melhoria de seus serviços e na importância de uma operação integrada com seu cliente, vai ao encontro dos conceitos discutidos na literatura. A atuação do PSL não pode ser individualista, ou seja, a de atuar buscando resultados isoladamente. Ele deve ter a visão de melhoria da CS de seu cliente e, por meio disso, oferecer um número de atividades e serviços que incorpore valor e novas oportunidades aos seus negócios.

\section{REFERÊNCIAS}

BERGLUND, M; LAARHOVEN P.V.; SHARMAN, G.; WANDEL, S. Third-Party Logistics: Is there Future? International Journal of Logistics Management, 10, 1, p. 59, 1999.

CAMBRA-FIERRO, J.F.; POLO-REDONDO, Y.. Creating satisfaction in the demandsupply chain: the buyers' perspective. Supply Chain Management: An International Journal, 13/3, p. 211-224, 2008.

CHAPMAN, R. L., SOOSAY, C., KANDAMPULLY, J. Innovation in Logistics Services and the New Bussiness Model: a Conceptual Framework. International Journal of Physical Distribution \& Logistics Management, v. 33 n. 7, p. 630-650, 2003.

DORNIER, P; ERNST, R.; FENDER, M.; KOUVELIS, P. Logística e Operações Globais. São Paulo: Atlas, 2000.

EISENHARDT, K. M. Building theories from case study research. Academy of Management Review, v. 14, n. 4, p. 532-550, 1989.

FIGUEIREDO, R. Seleção de Prestadores de Serviços Logísticos - Adequando o Proceso Seletivo a Cada Necessidade. Artigos Cel-Coppead - UFRJ - 2005, disponível em www.cel-coppead.com.br, acesso em 09/11/05.

FLEURY, M.T.L. e FLEURY, A. Construindo o conceito de competência. RAC Revista de Administração Contemporânea, edição especial, pp. 183-196, 2001.

JAAFAR, H.S.; RAFIQ, M. Logistics Outsourcing Practices in the UK: a Survey. International Journal of Logistics: Research and Applications, vol. 8, n. 4, p. 299-312, 2005.

HILLETOFTH, P. e HILMOLA, O. Role of logistics outsourcing on supply chain strategy and management - survey findings from Northern Europe. Strategic Outsourcing: an International Journal, vol. 3, n.1, pp. 36-61, 2010.

HOEK, REMKO I. VAN. UPS Logistics and to Move Towards 4 PL - Or Not? Disponível em: < www.csmp.org>. Acesso em: 30/03/06.

HOLWEG, M.; PIL, F. Theoretical perspectives on the coordination of supply chains. Journal of Operations management. Vol. 26, n.3, pp. 389-406, 2008. 
KANAGARETNAM K.; MESTELMAN, S.; NAINAR, S.M.K.; SHEHATA, M. Trust and reciprocity with transparency and repeated interactions. Journal of Business research, v.63, n.1, pg. 241-247, 2010.

KIRIDARAN, k.; MESTELMAN, S.; NAINAR, S.; SHEHATA, M. Trust and reciprocity with transparency and repeated interactions. Journal of Business research, vol. 63, n.1, pp. 241-247, 2010.

LANGLEY, C. J.; ALLEN, G. R. Third-Party Logistics Study 2004. Results and Findings of the 2004, Ninth Annual Study. Disponível em: www.tligatech.edu. Acesso em: $16 / 08 / 2005$.

LANGLEY e outros. 2009 Third-party logistics. Results and findings of the $14^{\text {th }}$ annual study. Disponível em: < www.3plstudy.com> Acesso em: 19/09/2010.

LONSDALE, C.; COX, A.; The historical development of outsourcing: the latest fad?" Industrial Management \& Data Systems, v. 100 n. 9, p. 444-450, 2000.

LIEB, ROBET. The year 2007 survey - Provider CEO perspectives on the current status and future prospects of the third party logistics industry in the Asia-Pacific region. International Journal of Physical Distribution \& Logistics Management, vol. 38, n.6, pp. 495-512, 2008.

LIEB, R.; BENTZ B. A. The Use of Third-Party Logistics Services by Large American Manufactures: The 2004 Survey. Transportation Journal, v. 44, n. 2, p. 5, 2005.

LIEB, K. J.; LIEB, R. C. Environmental sustainability in the third-party logistics (3PL) industry. International Journal of Physical Distribution \& Logistics management. Vol. 40, n. 7, pp.524-533, 2010.

MCKINNON, A. C.; GE, Y. Use of a Synchronised Vehicle Audit to Determine Opportunities for Improving Transport Efficiency in Supply Chain. International Journal of Logistics: Research and Applications, v. 7, n. 3, p. 219-238, 2004.

MIGUEL, P. A. C. Estudo de caso na engenharia de produção: estruturação e recomendações para sua condução. Produção, v. 12, n. 1, p.216-229, jan/abr-2007.

POWER, D; SHARAFALI, M; VIKRAM, B. Adding value through outsourcing contribution of $3 \mathrm{PL}$ services to customer performance. Management Research News, vol. 30, n. 3, pp. 228-235, 2007.

RATTEN, VANESSA. The Role of Learning and Information Dissemination in Logistics Alliances. Asia Pacific Journal of Marketing and Logistics, v. 16, n. 4, p. 65. 2004.

RYU, I.; SO, S.; KOO, C.. The role of partnership in supply chain performance. Industrial Management \& Data Systems. v. 109, n. 4, p. 496-514, 2009.

SAHAY, B.S. Supply chain collaboration: The key to value creation. Work Study, v.52, n.1, p.76-83, 2003. 
SELVIARIDIS, K.; SPRING, M. Third party logistics: a literature review and research agenda. The International Journal of Logistics management, vol. 18, n. 1, pp. 125150, 2007.

SINGH, P. F.; POWER, D. The nature and effectiveness of collaboration between firms, their customers and suppliers: a supply chain perspective. Supply Chain Management: An International Journal, 14/3, p.189-200, 2009.

STEFANSSON, GUNNAR. Collaborative Logistics Management and the Role of Third-Party Service Providers. International Journal Of Physical Distribution \& Logistics Management, v. 36, n.2, p. 76-92, 2005.

SVENSSON, GORAN. (2003), Sub-Contractor and Customer sourcing and the occurrence of disturbances in firms inbound and outbound logistics flows. Supply Chain Management: an International Journal, v. 8, n. 1, p. 41-56.

VAIDYANATHAN, GANESH. A Framework for Evaluating Third Party Logistics. Communications of the ACM, v. 48, n. 1, p. 89-94, 2005.

VIJAYVARGIYA, A. e DEY, A. K. Na analytical approach for selection of a logistics provider. Management Decision, vol. 48, n. 3, pp. 403-418, 2010.

VISSER, EVERT-JAN; KONRAD, KRIS \& SALDEN, ROEL. Developing 4Th Party Services: Empirical Evidence on the Relevance of Dynamic Transaction-cost Theory for Analyzing a Logistic System Innovation. 44Th European Regional Science Association - ERSA 2004 Congress, 2004.

VIVALDINI, M.; PIRES, S. R. I. Operadores Logísticos - Integrando operações em cadeias de suprimento. Editora Atlas, São Paulo, 2010.

WANKE, PETER. Impactos da Sofisticação Logística de Empresas Industriais nas Motivações para Terceirização. Revista Gestão e Produção, v. 11, n.3, p.1-20, 2004. 